\title{
US radiation report prompts bioethics move
}

Washington. A panel advising President Bill Clinton on radiation experiments conducted after World War Two has found "serious deficiencies" in the system for protecting human research subjects. Clinton was expected to announce the establishment of a National Bioethics Advisory Committee, to tackle the issues raised by the panel, when he received its final report on Tuesday.

In the report, the Advisory Committee on Human Radiation Experiments calls for a national effort "to ensure the centrality of ethics in the conduct of scientists whose research involves human subjects". It also recommends a shake-up of the system of non-specialist institutional review boards (IRBs) which has the task of maintaining research ethics.

But the panel concludes that the government does not owe any compensation to the thousands of unsuspecting subjects of the post-war radiation experiments, unless they were either physically harmed or had been systematically deceived. Experts said this ruling - if accepted by the administration and Congress - would probably restrict automatic compensation to a small number of subjects used in a handful of well-publicized experiments.

The report is the culmination of a huge, 18-month investigation that began when Hazel O'Leary, the energy secretary, promised to open up the records of the nuclear-related research undertaken by her department and its predecessors. With various degrees of reluctance, other branches of government then joined in a trawl through millions of documents on past radiation experiments (see Nature 368, 781; 1994).

According to several observers, the findings of the panel, which was chaired by Ruth Faden, a medical ethicist at Johns Hopkins University, Baltimore, Maryland, are much

\section{Omnibus science bill heads for the TV screen}

Washington. Science policy issues will receive a thorough airing on Capitol Hill next week, when the House of Representatives considers an omnibus science bill outlining almost $\$ 22$ billion of spending on research and development.

The authorization bill, which is being proposed by Robert Walker (Republican, Pennsylvania), chair of the House science committee, covers most government-sponsored research and development, except biomedical and defence research. It deals with all research spending at the National Aeronautics and Space Administration (NASA), the National Science Foundation (NSF), the Department of Energy and the Department of Commerce.

Walker says that having a single bill for all those agencies will "elevate science to the same kind of consideration that defence pri- more critical of existing research practice than had been expected. They follow a crucial decision of the panel, which was asked to focus chiefly on the period 1946-74, to check up on today's practice by conducting an extensive survey of 1,900 cancer and heart disease patients.

The report was welcomed, in public at least, by government officials responsible for upholding ethics in human subjects research. Gary Ellis, director of the Office for Protection from Research Risks (OPRR) at the National Institutes of Health (NIH), said that the panel had found "a wellrounded system", even though there was still some room for improvement. "We too have an interest in making the system better," he said.

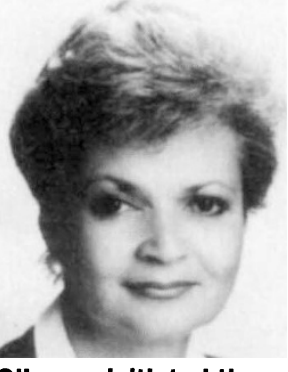

says that the panel did not intend to criticize the NIH office, which is "doing as much as it can with the resources it has which are pitiful". OPPR, whose main function is to educate researchers, has 15 members of staff and an annual budget of $\$ 2.2$ million. This year, it has held five workshops for around 1,000 scientists, and it circulates a newsletter to 5,500 addresses.

The panel's criticism of current research practice focused on two main problems: the failure of many research subjects to understand properly what they are letting themselves in for, and the difficulties of non-specialist institutional review boards (IRBs) in adequately supervising research on human subjects.

"There is reason to worry that partici-

orities have always had." The House is expected to allow two or three days from 10 October to debate the bill, giving US scientists with access to C-SPAN cable television a chance to see their paymasters at work.

The bill will propose cutting back next year's budget for these agencies from $\$ 24.5$ billion to $\$ 21.5$ billion. But Republicans say that the basic research component of that will hold steady at $\$ 6.7$ billion.

Democrats will try to restore various threatened budget items, including NASA's Mission to Planet Earth, the Department of Commerce's Advanced Technology Programme, and the Energy Department's conservation, solar energy and fusion programmes, and may even find some Republican allies. But the House is unlikely to overturn any major part of Walker's bill.

C. $\mathbf{M}$. pants in research may have unrealistic expectations both about the possibility they will personally benefit from participation, and about the discomfort, pain and suffering that sometimes accompany research," says the report. "This seems particularly to be the case in Phase I and Phase II drug trials."

The panel calls for new mechanisms to ensure that patients have a better understanding of these risks and - in particular - grasp the distinction between research and treatment. It adds that the IRBs are overwhelmed with work, chiefly because they must assess every research grant proposal submitted to NIH, including the vast majority which go unfunded.

According to Faden, the panel's decision not to recommend automatic compensation for all patients subjected unknowingly to radiation experiments came after careful consideration of how a remedy should match an offence. The report suggests that these patients should get a formal apology from the federal government. Compensation should be paid only if the patient was harmed, or if the government actively sought to keep information from patients or families "for the purpose of avoiding embarrassment or legal liability".

The committee's intensive search of research records appears to have unearthed few instances of wantonly unethical conduct that had not already surfaced in the press, or when Congress investigated the subject ten years ago. Faden said that she was happy with the cooperation received from all government agencies, although the Central Intelligence Agency (CIA), she said, was "a special case". According to the report, the CIA's record-keeping practices and cellular structure made it impossible to get a complete picture of the research it conducted on human subjects.

The panel recommended a new federal policy to safeguard the right to informed consent for the human subjects of secret government research, which it said continued, albeit on a small scale. It found that the secret release of radiation into the atmosphere, for research purposes, remained legal, and said that this should be overseen by suitably cleared inspectors from the Environmental Protection Agency.

All of this will resonate with that sector of the public that instinctively distrusts the federal government. But it is likely also to annoy those researchers who believe that sufficient safeguards are already in place to prevent any repetition of past mistakes.

Faden agrees there has been "dramatic progress" in research ethics over the past 50 years. "So there is a temptation to say there was a problem, and we have fixed it," she says. But that would be a big mistake; "there are still serious problems and we need to keep working at them."

Colin Macilwain 